\title{
Spreading a Medical Home Redesign: Effects on Emergency Department Use and Hospital Admissions
}

Robert J. Reid, $M D, P b D^{1,2}$

Eric A. Jobnson, $M A^{3}$

Clarissa Hsu, $\mathrm{PbD}^{2,3}$

Kelly Ebrlich, MS

Katie Coleman, $\mathrm{MSPH}^{3}$

Claire Trescott, $M D^{1}$

Michael Erikson, MSW

Tyler R. Ross, $M A^{3}$

David T. Liss, PbD, $M A^{2,3,5}$

DeAnn Cromp, $\mathrm{MPH}^{3}$

Paul A. Fishman, $\mathrm{PbD}^{2,3}$

${ }^{1}$ Group Health Physicians, Seattle, Washington

${ }^{2}$ School of Public Health, University of Washington, Seattle, Washington

${ }^{3}$ Group Health Research Institute, Seattle, Washington

${ }^{4}$ Group Health Cooperative, Seattle, Washington

${ }^{5}$ Division of General Internal Medicine \& Geriatrics, Northwestern University Feinberg School of Medicine, Chicago, Illinois

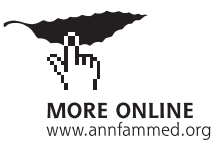

Conflicts of interest: Authors Jobnson, Hsu, Ebrlich, Coleman, Trescott, Erikson, Ross, and Fishman receive salary support from Group Health Cooperative. Authors Reid and Trescott are employees and sharebolders of Group Health Physicians, the physician group that is exclusively associated with Group Health Cooperative.

\section{CORRESPONDING AUTHOR}

Robert J. Reid, MD, PhD

Group Health Research Institute

1730 Minor Ave, Ste 1600

Seattle, WA 98101

reid.rj@ghc.org

\begin{abstract}
PURPOSE The patient-centered medical home $(\mathrm{PCMH})$ is being rapidly deployed in many settings to strengthen US primary care, improve quality, and control costs; however, evidence supporting this transformation is still lacking. We describe the Group Health experience in attempting to replicate the effects on health care use seen in a PCMH prototype clinic via a systemwide spread using Lean as the change strategy.
\end{abstract}

METHODS We used an interrupted time series analysis with a patient-month unit of analysis over a 4-year period that included baseline, implementation, and stabilization periods for 412,943 patients. To account for secular trends across these periods, we compared changes in use of face-to-face primary care visits, emergency department visits, and inpatient admissions with those of a nonequivalent comparison group of patients served by community network practices.

RESULTS After accounting for secular trends among network patients, patients empaneled to the PCMH clinics had $5.1 \%$ and $6.7 \%$ declines in primary care office visits in early and later stabilization years, respectively, after the implementation year. This trend was accompanied by a 123\% increase in the use of secure electronic message threads and a 20\% increase in telephone encounters. Declines were also seen in emergency department visits at 1 and 2 years $(13.7 \%$ and $18.5 \%$ ) compared with what would be expected based on secular trends in network practices. No statistically significant changes were found for hospital admissions.

CONCLUSIONS The Group Health experience shows it is possible to reduce emergency department use with PCMH transformation across a diverse set of clinics using a clear change strategy (Lean) and sufficient resources and supports.

Ann Fam Med 2013;11:S19-S26. doi:10.1370/afm.1476.

\section{INTRODUCTION}

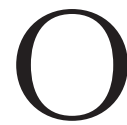
$\mathrm{n}$ the basis of convincing evidence that strong primary care is associated with lower costs and improved quality of care, ${ }^{1}$ there is a rapid move to implement the patient-centered medical home (PCMH) across the United States in various settings including independent practices, integrated delivery systems, community health centers, and large government systems. ${ }^{2-5}$ Although these demonstration initiatives share the PCMH guiding principles, ${ }^{6}$ they differ considerably with respect to their settings, organizational structures, payer participation, intervention components, and implementation strategies. ${ }^{2,7}$ Early results are promising ${ }^{8,9}$ but more extensive and rigorous evaluations are needed. ${ }^{8-11}$ As substantial infrastructure investments are often required to build medical home capabilities, ${ }^{12}$ policy makers and health plan leaders are particularly interested in whether and when adoption of this model results in overall cost savings. The evidence remains largely lacking in 
this regard but suggests that savings are most likely to accumulate from avoidance of downstream emergency department (ED) visits and hospital admissions.

Since 2006, Group Health Cooperative, a large nonprofit, consumer-governed, integrated health insurance and care delivery system in the Pacific Northwest, has pioneered the medical home redesign. In contrast to small independent practices in the United States, Group Health has traditionally supported its primary care clinicians with multidisciplinary teams (including nurses and pharmacists), a systemwide electronic health record, a quality improvement department that produces evidence-based clinical guidelines, an integrated specialist medical group, a consulting nurse service, and a complex case management program (Supplemental

Appendix, available online at http://annfammed.

$\forall \boldsymbol{m}_{\mathbf{l}}$ org/content/11/Suppl_1/S19/suppl/DC1). Even with these supports, however, primary care clinicians faced many challenges and prompted Group Health to develop a PCMH prototype in one high-functioning clinic and test it over a 2 -year period..$^{13}$ By the end of the second year, compared with other clinics in the same system, the prototype clinic had less clinician burnout, improved patient experience, and better quality of care. A key feature of the prototype was to expand access and manage demand for face-to-face patient visits with so-called virtual medicine (secure electronic messaging and telephone encounters). Primary care use saw substantial shifts, with $80 \%$ more secure message threads, $5 \%$ more telephone encounters, and $6 \%$ fewer (though longer) face-to-face visits. Compared with their control counterparts, patients in the prototype clinic also experienced $29 \%$ fewer emergency visits and 6\% fewer hospitalizations. These changes resulted in overall cost savings that approached statistical significance $(P=.076)$, suggesting that the investments in staffing that may have been recouped with a modest return on investment. ${ }^{14}$

In part on the basis of these findings, beginning in January 2009, Group Health refined and spread its $\mathrm{PCMH}$ redesign across its system of 26 owned and operated clinics across Washington State and northern Idaho. Given the well-described challenges in spreading health system innovations from one setting to another, it was unknown whether the findings seen in the prototype clinic (which had a prior history of high quality and strong adaptive reserve) could be replicated across the entire system. This effort was one of the first to spread a highly standardized PCMH redesign to clinics that vary in size (from 6,000 to $>40,000$ enrollees), community setting (urban and rural), and populations served (eg, $12 \%$ to $24 \%$ Medicare). Described in detail elsewhere ${ }_{1}^{15}$ the design of the PCMH spread identified and adapted key changes made in the prototype so that the core components would be applicable to the other clinics. As with the prototype, Group Health committed resources to add clinical and support staff to reduce panel sizes (target: $1,800-2,000$ patients), reduce the number of faceto-face visits to 2 per hour, and accommodate new PCMH tasks. The changes were packaged into core modules, and implementation was staggered across clinics from January 2009 to March 2010. In contrast to other demonstration projects that use learning collaboratives or coaching of practices to implement the PCMH across multiple clinics, ${ }^{2,16}$ Group Health adopted the tools and techniques of Lean ${ }^{17}$ (also known as the Toyota production system) to standardize and drive implementation of the core PCMH changes. ${ }^{15}$

Our prior work has shown rapid uptake of the model, with $80 \%$ to $100 \%$ of clinics meeting the initial implementation targets by 12 months for most of the key process measures (eg, 100\% of visits with documentation of previsit preparation by medical assistants). ${ }^{15}$ After implementation of the core PCMH modules, teams engaged in a 24 -month stabilization period composed of rapid process improvement cycles to engage teams in refining the changes to meet their local challenges and needs. In October 2010, all Group Health clinics were recognized by the National Committee for Quality Assurance (NCQA) with its highest $\mathrm{PCMH}$ recognition (Level 3), although many components (eg, electronic health record registries) had been in use before the PCMH transformation.

We studied the degree to which Group Health was able to replicate some of the main changes in health care use seen in the prototype throughout its entire system. We focused on changes in primary care visits, ED visits, and inpatient admissions because PCMHs are believed to realize cost savings by substituting high-cost hospital-based care with lower-cost primary care. On the basis of the prototype findings, we hypothesized that, after accounting for secular trends in use with patients enrolled in a statewide network of contract providers maintained by Group Health, patients enrolled at the Group Health clinics would have fewer face-to-face primary care office visits, ED visits, and inpatient admissions in the stabilization period. We describe initial utilization patterns during the implementation year and hypothesized that the main changes would materialize and be sustained in the stabilization years.

\section{METHODS}

We use an interrupted times series study design with a patient-month unit of analysis to compare patients' use of health care for a 4-year period spanning January 2008 to December 2011. This period includes 1 year before, 
1 year during, and 2 years after $\mathrm{PCMH}$ implementation in the Group Health-owned and-operated clinics. To account for secular trends in our analysis, we estimated the changes in health care use over time in a nonequivalent population of Group Health enrollees who were cared for in a statewide network of practices composed of 875 primary care clinicians, most often located in communities where Group Health does not have clinics or directly employ physicians. These temporal effects were modeled using piecewise linear splines, with knots in January of each calendar year. We verified the appropriateness of using network patient use as a comparison by examining and comparing temporal trends for each use variable in the 2 years before the PCMH spread. There were no statistical differences in the trend over time in any of the use variables we analyzed between patients seen in the owned and operated clinics and in the network setting, which helps validate the use of the use of this nonequivalent comparison group as a basis for assessing the PCMH's impact on health care use among patients seen in the Group Health clinics.

As spread of the PCMH was staggered by clinics, we constructed a set of time periods for individuals enrolled in the Group Health clinics. Patient-months were organized into 4 time periods: a baseline period (the 12-14 months before the date of the clinic's PCMH implementation), an implementation period (year 1: the year after PCMH implementation began), an early stabilization period (year 2), and a late stabilization period (year 3). Our estimates of the PCMH effect per time period reflect the average difference in use in each period compared with what would be expected based on trends in the network. To avoid a cointervention effect, we excluded enrollees empaneled to 7 network practices participating in the Washington State Medical Home Collaborative, a statewide effort to introduce PCMHs to community clinics. ${ }^{18}$ Our analysis included all Group Health enrollees (receiving care from a Group Health or network practice) as of January 1, 2008, across the 4-year time period, and excluded patient-months only after a patient disenrolled, died, or did not have a 12-month enrollment history to enable the calculation of the Aggregated Diagnosis Group (ADG) comorbidity measures (discussed below). Because Group Health applied the $\mathrm{PCMH}$ spread redesign ${ }^{15}$ to the prototype clinic in the same way as it did to the other clinics, we did not exclude patients at the prototype clinic from this study.

Using previously documented methods ${ }^{19}$ we extracted data on health care use from Group Health's automated clinical and administrative data systems. These databases capture all care provided to enrollees at Group Health's owned and operated facilities and from claims submitted by external clinicians and facilities. For this study, we analyzed a subset of components of health care use hypothesized to be sensitive to the PCMH model: primary care office visits, ED visits, and inpatient admissions (total and ambulatory care-sensitive admissions). ${ }^{20,21}$ As Group Health's PCMH model relies on aggressive use of secure electronic messaging and telephone care, ${ }^{14,15}$ we also examined trends over time in these "virtual" services for those patients enrolled in the Group Health clinics. Similar data were not available for network patients, as these services are not generally reimbursable through fee-for-service claims.

For each patient, we extracted demographic and insurance variables at baseline, including age, sex, income, education, insurance source, and markers of insurance-related patient cost sharing (high-deductible plans, drug coverage, well-care waivers). Using methods developed by Kreiger, ${ }^{22}$ we created the ecologic income and education variables from 2000 census data aggregated to census tracts. To reflect urban and rural status, we classified residential location using rural-urban commuting area codes (RUCAs, version 2.0), ${ }_{1}^{23}$ which classifies zip codes into relative geographic densities based on overall population counts and commuting patterns. For this study, we aggregated RUCA codes into urban areas (1.0-3.0), micropolitan and large rural areas (4.06.1), and small rural/isolated areas (7.0-10.6).

We used the 32 ADGs, the base categories of the Adjusted Clinical Group (ACG) system, to account for diagnosis mix and comorbidity burden. ${ }^{24-31}$ We also used Resource Utilization Bands (RUBs), the ACG system's terminal morbidity groupings, to summarize the morbidity mix across populations. The ACG system is widely used to adjust for differences in case mix among populations receiving health services in outpatient settings.

All analyses were performed with generalized estimating equation (GEE) analyses in PROC GENMOD of SAS (SAS Institute, Inc, version 9.2), using an identity link and Gaussian error term, with empirical standard errors for the regression coefficients. To control for seasonality, we also added indicator variables for each calendar month to the regression analyses. Consistent with current analytic recommendations ${ }^{32}$ and because the unit of intervention at Group Health was the clinic, clustering was accounted for at both the patient and practice level. The regression analyses are represented by the following equation:

$$
\begin{gathered}
\text { Util } l_{i, m}=\beta_{0} m+\beta_{1} \max (m-12,0)+\beta_{2} \max (m-24,0)+ \\
\beta_{3} \max (m-36,0)+\alpha_{0}\left(I\left(k_{i} \in(1,2,3)\right)\right)+ \\
\alpha_{1}\left(I\left(k_{i} \in(4,5,6)\right)\right)+\alpha_{2}\left(I\left(k_{i} \in(7,8,9)\right)\right)+\alpha_{3}\left(I\left(k_{i} \in(10,11,12)\right)\right)+ \\
\alpha_{4}\left(I\left(k_{i} \in(13 \ldots 24)\right)\right)+\alpha_{5}\left(I\left(k_{i} \in(25 \ldots 36)\right)\right)+\sum_{b=1}^{c} \delta_{b} x_{b}
\end{gathered}
$$

where $m$ describes the study month (range, 1-48), ki describes the individual-specific time since PCMH 
implementation for individual $i$ (range, 1-36), and the $x b$ variables are the demographic, case mix, and calendar month variables. The $I()$ function returns 1 if its contents are true and $\mathrm{o}$ if otherwise. The $\beta$ coefficients describe the linear splines that adjust for secular trends, the $\alpha$ coefficients describe the effect of the $\mathrm{PCMH}$ implementation, and the $\delta$ coefficients describe the adjustment for demographics, case mix, and calendar month.

All case mix variables were held fixed from January 2009. Because another initiative aimed at reducing unnecessary hospital admissions (by hospitalists and transition nurses) was conducted concurrently during the spread of the $\mathrm{PCMH},{ }^{33}$ we conducted a sensitivity analysis on the hospital admission regression analyses to remove a possible cointervention effect by adjusting for monthly hospital ED-to-admission transition rates for the hospitals participating in this concurrent initiative. Similarly, because in January 2009 an urban Group Health urgent care center expanded from evening and weekend hours to 24-hour availability, we also conducted sensitivity analyses excluding patients enrolled in the 4 Group Health clinics who account for the majority of visits at this urgent care center. The Group Health Institutional Review Board approved this study.

\section{RESULTS}

A total of 412,943 individuals were enrolled at Group Health on January 1, 2009, and were included in the study; $74 \%$ were empaneled to a Group Health clinic and the remainder to privately owned practices serving Group Health-insured patients (Table 1). The average duration of study enrollment per individual was 44 months. As would be expected of a largely commercially insured population, the majority of enrollees were working age (aged 17 to 65 years, 66\%), lived in neighborhoods with medium to high levels of education (at least high school graduates, 89\%), and had 2001 median family incomes that were higher $(\$ 57,893)$ than the state average $(\$ 45,761) .{ }^{34}$ Most enrollees carried a health maintenance organization insurance product that limited their choice of clinician (80\%), but they had rel-
Table 1. Baseline Characteristics of the Study Populations, 2009

\begin{tabular}{|c|c|c|c|}
\hline Characteristic & $\begin{array}{l}\text { Group Health } \\
\text { Practices } \\
(n=305,578)\end{array}$ & $\begin{array}{c}\text { Network } \\
\text { Practices } \\
(n=107,365)\end{array}$ & $\begin{array}{c}\text { Total } \\
(\mathrm{N}=412,943)\end{array}$ \\
\hline Age, mean (SD), y & $43.5(22.6)$ & $40.4(21.9)$ & $42.7(22.5)$ \\
\hline \multicolumn{4}{|l|}{ Age-group, No. (\%) } \\
\hline $1-5$ years & $12,889(4.2)$ & $5,104(4.9)$ & $17,993(4.4)$ \\
\hline $6-11$ years & $18,307(5.9)$ & $8,050(7.7)$ & $26,357(6.4)$ \\
\hline $12-16$ years & $19,156(6.2)$ & $8,283(7.9)$ & $27,439(6.6)$ \\
\hline $17-34$ years & $57,226(18.5)$ & $18,328(17.5)$ & $75,554(18.3)$ \\
\hline $35-44$ years & $37,959(12.3)$ & $13,556(13.0)$ & $51,525(12.5)$ \\
\hline $45-64$ years & $109,707(35.6)$ & $38,753(37.1)$ & $148,461(36.0)$ \\
\hline $65-74$ years & $26,836(8.7)$ & $6,644(6.4)$ & $33,480(8.1)$ \\
\hline $75-84$ years & $17,860(5.8)$ & $4,300(4.1)$ & $22,160(5.4)$ \\
\hline$\geq 85$ years & $8,563(2.8)$ & $1,411(1.4)$ & $9,974(2.4)$ \\
\hline \multicolumn{4}{|l|}{$\begin{array}{l}\text { Education, neighborhood level, } \\
\text { No. (\%) }\end{array}$} \\
\hline High & $13,679(40.1)$ & $37,118(35.5)$ & $160,797(39.0)$ \\
\hline Medium & $152,462(49.4)$ & $53,327(51.1)$ & $205,789(49.8)$ \\
\hline Low & $32,331(10.5)$ & $13,985(13.4)$ & $46,316(11.2)$ \\
\hline $\begin{array}{l}\text { Family income, neighborhood } \\
\text { level, median (SD), \$ }\end{array}$ & $59,882(19,833)$ & $51,909(15,122)$ & $57,787(19,037)$ \\
\hline \multicolumn{4}{|c|}{ Residence location, RUCA, No. (\%) } \\
\hline Urban & $269,515(96.1)$ & $75,241(72.0)$ & $371,756(90.0)$ \\
\hline Metropolitan/large rural & $5,868(1.9)$ & $19,598(18.8)$ & $25,466(6.2)$ \\
\hline Small rural/isolated areas & $2,811(0.9)$ & $7,472(7.2)$ & $10,283(2.5)$ \\
\hline Not mapped & $3,309(1.1)$ & $2,129(2.0)$ & $5,438(1.3)$ \\
\hline \multicolumn{4}{|l|}{ Insurance segment, No. (\%) } \\
\hline Medicare & $55,435(18.0)$ & $13,038(12.5)$ & $68,473(16.6)$ \\
\hline Medicaid & $9,196(3.0)$ & $838(0.8)$ & $10,034(2.4)$ \\
\hline Commercial/self-pay & $221,190(71.7)$ & $86,904(83.2)$ & $308,064(74.6)$ \\
\hline Individual or family plan & $22,682(7.4)$ & $3,660(3.5)$ & $26,342(6.4)$ \\
\hline \multicolumn{4}{|l|}{ Health plan product, No. (\%) } \\
\hline $\mathrm{HMO}$ & $257,466(83.5)$ & $73,383(70.3)$ & $330,849(80.1)$ \\
\hline $\mathrm{PPO} / \mathrm{POS}$ & $51,037(16.5)$ & $31,057(29.7)$ & $82,094(19.9)$ \\
\hline \multicolumn{4}{|l|}{ Insurance benefit design, No. (\%) } \\
\hline Well-care waiver & $203,166(66.0)$ & $65,949(63.0)$ & $269,115(65.2)$ \\
\hline High-deductible plan & $3,157(1.0)$ & $997(1.0)$ & $4,154(1.0)$ \\
\hline Drug coverage & $267,857(87.0)$ & $95,880(92.0)$ & $363,737(88.1)$ \\
\hline \multicolumn{4}{|l|}{$\begin{array}{l}\text { Morbidity, ACG RUB category, } \\
\text { No. (\%) }\end{array}$} \\
\hline 0 (nonusers) & $37,417(7.1)$ & $11,134(6.0)$ & $48,551(6.8)$ \\
\hline 1 (low morbidity) & $36,332(6.9)$ & $12,414(6.7)$ & $48,746(6.8)$ \\
\hline 2 & $53,530(10.1)$ & $19,901(10.7)$ & $73,431(10.3)$ \\
\hline 3 & $133,188(25.2)$ & $45,905(24.8)$ & $179,093(25.1)$ \\
\hline 4 & $31,992(6.0)$ & $10,613(5.7)$ & $42,535(6.0)$ \\
\hline 5 (high morbidity) & $14,142(2.7)$ & $4,026(2.2)$ & $18,168(2.5)$ \\
\hline
\end{tabular}




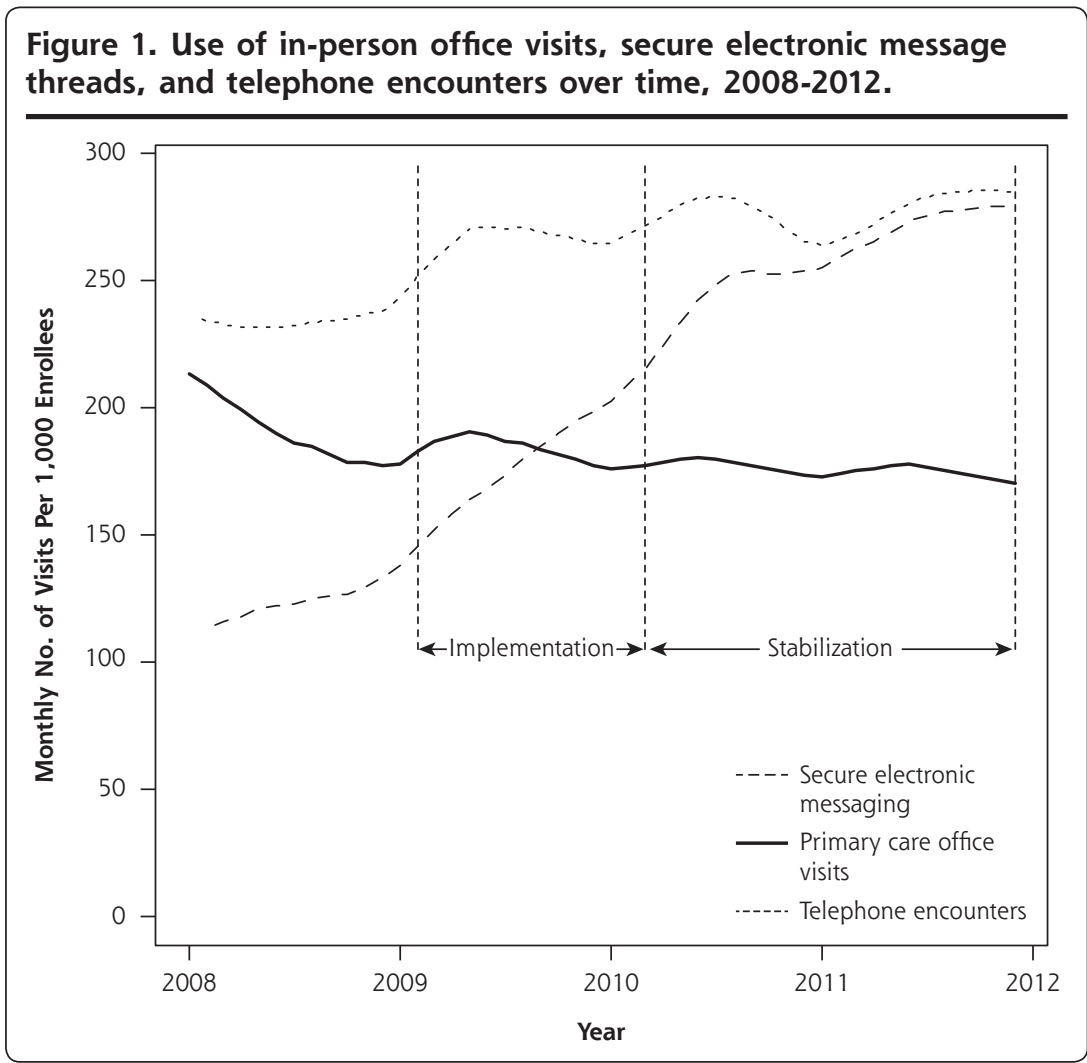

dation in the early stabilization year (-9.7 visits per 1,000 per month, $-5.1 \%)$ and late stabilization year $(-12.6$ visits per 1,000 per month, $-6.7 \%)$. In unadjusted analyses, ED visit rates in the baseline period were 12.6 visits per 1,000 among patients empaneled to at Group Health clinic vs 16.7 visits per 1,000 for patients empaneled to community network practices. Regression results also showed declines in ED visits during the last 3 quarters of the implementation period that persisted in the early stabilization year $(-1.73$ visits per 1,000 per month, $-13.7 \%)$ and late stabilization year $(-2.31$ visits per 1,000 per month, $-18.3 \%$ ). These findings were unchanged in the sensitivity analyses where an expansion of hours in a single urgent care center was accounted for by excluding patients empaneled to clinics in its catchment area (data not shown).

atively rich insurance benefits, such as a well-care insurance waiver $(65 \%)$, prescription drug coverage (88\%), and plans not having a high deductible (99\%). Although most patients had low morbidity levels as characterized by RUBs, a sizable fraction (14\%) were rated as having high or very high morbidity burdens.

Similar to what was found in the prototype clinic, ${ }^{14}$ spread of the PCMH model across the Group Health system was characterized by steep increases in secure electronic message threads and telephone encounters in the implementation and early stabilization years (Figure 1). From 2008 to 2011, the unadjusted number of secure message threads per 1,000 population increased by $123 \%$ and telephone encounters increased by $20 \%$. Also, similar to the prototype findings, overall use of face-to-face primary care visits declined by $4.5 \%$.

Table 2 shows the regression analysis results accounting for case mix and the secular trends seen for network patients in face-to-face visits, ED visits, and inpatient admissions. Compared with what would be expected with no PCMH implementation in these periods on the basis of secular trends in the network, patients empaneled to the PCMH clinics saw a shortlived increase in the number of face-to-face primary care visits per 1,000 patients in the first 2 quarters of the implementation period; however, there was a decline in the late implementation period, and consoli-
Although there were some transitory effects in the early implementation period, we found no statistically significant differences in the trend for either total inpatient admissions or ambulatory care-sensitive admissions in the early or late stabilization years. These latter findings were unchanged in a sensitivity analysis that accounted for the concurrent hospital-based intervention to reduce unnecessary admissions by including the monthly hospital-specific ED-to-admission transition rates for the participating hospitals in the models (data not shown).

\section{DISCUSSION}

\section{Key Findings}

Consistent with the findings from the prototype, spreading the PCMH model across all clinics was associated with a shift away from face-to-face primary care office visits toward greater use of secure message threads and telephone encounters, which represented approximately $77 \%$ of primary care contacts by the end of the study period. With the PCMH implementation, Group Health patients experienced 1.73 fewer ED visits per month per 1,000 enrollees $(-13.7 \%)$ in the year period without the $\mathrm{PCMH}$, based on case mix-adjusted secular trends in the community network. This difafter implementation than would be expected in this 


\section{Table 2. Adjusted Changes in Use for PCMH Patients Relative to Nonequivalent Control Patients}

Measure of Use and Period
Monthly primary care office visits
per 1,000 enrollees
Implementation (year 1)
Q1
Q2
Q3
Q4

Early stabilization (year 2)

Late stabilization (year 3)

Monthly ED visits per 1,000 enrollees

Implementation (year 1)

Q1
Q2
Q3

Early stabilization (year 2)

Late stabilization (year 3)

Monthly inpatient admissions (total)

per 1,000 enrollees

Implementation (year 1)

Q1

Q2

Q3

Q4

Early stabilization (year 2)

Late stabilization (year 3)

Inpatient admissions (total;

ACS conditions) per 1,000 enrollees

Implementation (year 1)

Q1

Q2

Q3

Q4

Early stabilization (year 2)

Late stabilization (year 3)

ED = emergency department; $\mathrm{PCMH}$ = patient-centered medical home; $\mathrm{ACS}$ = ambulatory care sensitive; $A D G=$ adjusted diagnosis group

${ }^{a}$ Estimated differences derived from regression models in the change in use for PCMH patients compared with nonequivalent control patients adjusted for age, sex, education, family income, residence location, insurance segment, health plan product, insurance benefit design, ADG mix, and calendar month. what would be expected without the PCMH for either total or ambulatory care-sensitive inpatient admissions, however. The way in which the model was spread may have been less effective for this measure of use, because of local circumstances of the prototype clinic (such as the admission practices at the main referral hospital) or because of relatively low rates of hospitalization at baseline in the local areas. Our findings also diverge from those in the Geisinger health system as studied by Gilfillan and colleagues, who found an $18 \%$ cumulative reduction in all-cause admissions. ${ }^{36}$ The divergence in findings may be explained, at least in part, by the Geisinger emphasis on embedded and integrated nurse case management for patients at high risk for hospitalization, an intervention component not featured at Group Health in its PCMH redesign. Although our study results have uncertain generalizability to PCMH demonstration efforts in settings less organized and supported than Group Health (see the Supplemental Appendix for a detailed description, available online at http:// annfammed.org/content/11/Suppl_1/ S19/suppl/DC1), a key finding that is likely transportable elsewhere is the importance of using a clear leadership, management, and change strategy to enable and sustain practice changes across multiple care sites.

\section{Strengths and Limitations}

This study has a number of notable strengths. Rather than studying volunteer practices, the patients and practices studied represent the entire

ference from the expected persisted and increased in the second year after implementation. The changes in face-to-face and ED use suggest Group Health was successful in spreading these prototype results to its whole system using a Lean implementation strategy. Future analyses will examine variability of the effects on health care use across the Group Health clinics and the influence of "practice reserve," ${ }^{135}$ staffing adequacy, and other likely key determinants of success.

In contrast to the prototype findings, ${ }_{1}^{14}$ where a small decrease was noted on inpatient admissions, we detected no differences in the stabilization years from complement of primary care delivered to an enrolled population in a large health system. Also, by relying on population-based data extending across multiple years from both the intervention practices as well as nonintervention network practices, we were able to use an interrupted time series study design with a nonequivalent comparison group, considered a strong evaluation design for nonrandomized natural experiments such as this. ${ }^{37}$ We were able to measure trends in ED use and hospital admissions for a 2-year time frame after implementation when $\mathrm{PCMH}$ effects are expected to emerge. Although trends in secure mes- 
sage threads and telephone visits were not available in the comparison practices, the data systems permitted the examination of these trends in the clinics to which the PCMH was spread. To our knowledge, this study is one of the first to examine changes in health care use for a practice transformation wherein Lean was chosen as the change strategy. We believe this is an important contribution given the growing adoption of Lean in health care environments across the country. ${ }^{17,38-40}$

The study has important limitations, however. As the study was not randomized and lacked a true control group, we may be missing important unmeasured confounders. In particular, we may not have accounted for other cointerventions or ecologic variables that differentially affected our study or comparison populations. We believe that these effects are likely to be local and transient because of our close communication with system leaders. Furthermore, we do not believe such unmeasured effects are likely to extend across all the study or comparison populations, and thus are less likely to result in important biases. We restricted our analysis to the effects of the PCMH on health care use in hospital settings (admissions and emergency departments) and did not examine changes for other relevant health service use categories, including specialty care, behavioral health, urgent care, and use of laboratory services, radiology, and home health. These analyses are ongoing. As well, we have no data on use of secure electronic messaging in the comparison group practices because they are nonreimbursable; thus, we cannot compare trends over time in e-communication technologies. At Group Health, the PCMH represented a complex system redesign that involved many changes implemented in rapid succession, and we did not attempt to determine which PCMH components were responsible for the effects. We also recognize that Group Health may be unique in its $\mathrm{PCMH}$ operational model, the level of baseline infrastructure including information technology and team staffing, the largely capitated revenue streams with salary-based physician compensation, and its Lean approach to PCMH transformation, all of which may limit generalizability. With the introduction of accountable care organizations built on PCMHs, many of which rely on advanced information technology and introduce partial or full capitation, we believe that lessons learned from integrated systems are increasingly relevant to other settings, however.

\section{Implications}

Group Health's experience in spreading its $\mathrm{PCMH}$ model shows that achieving PCMH transformation across a diverse set of primary care clinics is possible with a clear change strategy (Lean) and sufficient resources and supports. PCMH transformation was accompanied by significant changes in use across the system including reduced ED use. Although decreasing ED use is an early indicator of success in this systemwide PCMH implementation, further, forthcoming evaluation will examine its effect on patient experience, quality of care, and the total costs of care. It is important to note that we did not find a lasting $\mathrm{PCMH}$ effect on hospitalization with Group Health's PCMH operational model. We believe that to reduce hospitalizations, a more deliberate focus on high-risk primary care case management is likely required. Although we acknowledge that many issues need further exploration regarding the $\mathrm{PCMH}$, we believe this study makes an important contribution to the growing body of evidence on the outcomes of the PCMH.

To read or post commentaries in response to this article, see it online at http://www.annfammed.org/content/11/Suppl_1/S19.

Key words: medical home; primary health care; family practice; delivery of health care; Lean; practice-based research; change management

Submitted July 9, 2012; submitted, revised, November 13, 2012 : accepted November 19, 2012.

Funding support: Support was provided by the Agency for Healthcare Research and Quality (R18 HS019129) and Group Health Cooperative.

Disclaimer: The views expressed here are solely the authors and do not necessarily represent the views of the funders.

\section{References}

1. Starfield B, Shi LY, Macinko J. Contribution of primary care to health systems and health. Milbank Q. 2005;83(3):457-502.

2. Bitton A, Martin C, Landon BE. A nationwide survey of patient centered medical home demonstration projects. J Gen Intern Med. 2010;25(6):584-592.

3. Marshall RC, Doperak M, Milner M, et al. Patient-centered medical home: an emerging primary care model and the military health system. Mil Med. 2011;176(11):1253-1259.

4. Klein S. The Veterans Health Administration: Implementing PatientCentered Medical Homes in the Nation's Largest Integrated Delivery System. New York, NY: The Commonwealth Fund; 2011:1537.

5. Adashi EY, Geiger HJ, Fine MD. Health care reform and primary care-the growing importance of the community health center. N Engl J Med. 2010;362(22):2047-2050.

6. American Academy of Family Physicians. Joint principles of a patient-centered medical home released by organizations representing more than 300,000 physicians. 2007. http://www.aafp.org/ online/en/home/media/releases/2007/20070305pressrelease0.html. Accessed June 20, 2008.

7. Patient-Centered Primary Care Collaborative. Patient-centered medical home pilots $\&$ demonstrations (self-reported). 2012. http://www. pcpcc.net/pcpcc-pilot-projects. Accessed June 19, 2012.

8. Williams JW, Jackson GL, Powers BJ, et al. The Patient-Centered Medical Home. Closing the Quality Gap: Revisiting the State of the Science. Evidence Report No. 208. (Prepared by the Duke Evidence-based Practice Center under Contract No. 290-2007-10066-I.) Rockville, MD: Agency for Healthcare Research and Quality; 2012. AHRQ publication 12-E008-EF. 
9. Peikes D, Zutshi A, Genevro JL, Parchman ML, Meyers DS. Early evaluations of the medical home: building on a promising start. Am J Manag Care. 2012;18(2):105-116.

10. Crabtree BF, Chase SM, Wise CG, et al. Evaluation of patient centered medical home practice transformation initiatives. Med Care. 2011;49(1):10-16.

11. Barr MS. The need to test the patient-centered medical home JAMA. 2008;300(7):834-835.

12. Nocon RS, Sharma R, Birnberg JM, Ngo-Metzger Q, Lee SM, Chin $\mathrm{MH}$. Association between patient-centered medical home rating and operating cost at federally funded health centers. JAMA. 2012; 308(1):60-66

13. Larson EB, Reid R. The patient-centered medical home movement: why now? JAMA. 2010;303(16):1644-1645.

14. Reid RJ, Coleman K, Johnson EA, et al. The group health medical home at year two: cost savings, higher patient satisfaction, and less burnout for providers. Health Aff (Millwood). 2010;29(5):835-843.

15. Hsu C, Coleman K, Ross TR, et al. Spreading a patient-centered medical home redesign: a case study. J Ambul Care Manage. 2012; 35(2):99-108.

16. Nutting PA, Crabtree BF, Stewart EE, et al. Effect of facilitation on practice outcomes in the National Demonstration Project model of the patient-centered medical home. Ann Fam Med. 2010;8(Suppl 1): S33-S44, S92.

17. Womack JP, Jones DT. Lean Solutions: How Companies and Customers Can Create Value and Wealth Together. New York, NY: Free Press; 2005

18. Patient-Centered Primary Care Collaborative. Washington PatientCentered Medical Home Collaborative. Washington, DC: Patient-Centered Primary Care Collaborative; 2009

19. Reid RJ, Fishman PA, Yu O, et al. Patient-centered medical home demonstration: a prospective, quasi-experimental, before and after evaluation. Am J Manag Care. 2009;15(9):e71-e87.

20. Zeng F, O'Leary JF, Sloss EM, Lopez MS, Dhanani N, Melnick G. The effect of Medicare health maintenance organizations on hospitalization rates for ambulatory care-sensitive conditions. Med Care. 2006;44(10):900-907.

21. Agency for Healthcare Research and Quality. Prevention quality indicators overview. AHRQ Quality Indicators. 2004. http://www. qualityindicators.ahrq.gov/Modules/pqi_overview.aspx. Accessed Sep 1, 2008.

22. Krieger N. Overcoming the absence of socioeconomic data in medical records: validation and application of a census-based methodology. Am J Public Health. 1992;82(5):703-710.

23. Hart LG, Larson EH, Lishner DM. Rural definitions for health policy and research. Am J Public Health. 2005;95(7):1149-1155.

24. Starfield B, Weiner J, Mumford L, Steinwachs D. Ambulatory care groups: a categorization of diagnoses for research and management. Health Serv Res. 1991;26(1):53-74.

25. Weiner JP, Starfield BH, Steinwachs DM, Mumford LM. Development and application of a population-oriented measure of ambulatory care case-mix. Med Care. 1991;29(5):452-472.
26. Reid RJ, Evans RG, Barer ML, et al. Conspicuous consumption: characterizing high users of physician services in one Canadian province. J Health Serv Res Policy. 2003;8(4):215-224.

27. Reid RJ, MacWilliam L, Verhulst L, Roos N, Atkinson M. Performance of the ACG case-mix system in two Canadian provinces. Med Care. 2001;39(1):86-99.

28. Reid RJ, Roos NP, MacWilliam L, Frohlich N, Black C. Assessing population health care need using a claims-based ACG morbidity measure: a validation analysis in the province of Manitoba. Health Serv Res. 2002;37(5):1345-1364

29. Rivara FP, Anderson ML, Fishman P, et al. Healthcare utilization and costs for women with a history of intimate partner violence. Am J Prev Med. 2007;32(2):89-96.

30. Verhulst L, Reid R, Forrest C. Hold it-my patients are sicker! The importance of case-mix adjustment to practitioner profiles in British Columbia. BC Med J. 2001;43(6):328-333.

31. Bonomi AE, Anderson ML, Rivara FP, Thompson RS. Health care utilization and costs associated with physical and nonphysical-only intimate partner violence. Health Serv Res. 2009;44(3):1052-1067.

32. Peikes D, Dale DC, Lundquist E, Genervo J, Meyers DS. Building the Evidence Base for The Medical Home: What Sample and Sample Size Do Studies Need? White paper (prepared by Mathematica Policy Research under contract HHSA290200900019I TO2). Rockville, MD: Agency for Healthcare Research and Quality; October 2011. AHRQ publication 11-0100-EF.

33. Alliance of Community Health Plans. Investing in Outcomes, Creating Value: Group Health Cooperative. 2009. http://www.achp.org/files. php?force\&file=/ACHP_GroupHealth_CaseStudy_223348370.pdf. Accessed June 26, 2012.

34. Office of Financial Management. Median household income estimates: 1989 to 2010 and projection for 2011. http://www.ofm. wa.gov/economy/hhinc/. Accessed June 12, 2012.

35. Miller WL, Crabtree BF, Nutting PA, Stange KC, Jaén CR. Primary care practice development: a relationship-centered approach. Ann Fam Med. 2010;8(Suppl 1):S68-S79, S92.

36. Gilfillan RJ, Tomcavage J, Rosenthal MB, et al. Value and the medical home: effects of transformed primary care. Am J Manag Care. 2010;16(8):607-614.

37. Shadish WR, Cook TD, Campbell DT. Experimental and Quasi-Experimental Designs for Generalized Causal Inference. 2nd ed. Boston, MA: Houghton Mifflin; 2001.

38. Graban M. Lean Hospitals: Improving Quality, Patient Safety, and Employee Satisfaction. Boca Raton: CRC Press; 2009.

39. Casey JT, Brinton TS, Gonzalez CM. Utilization of Lean management principles in the ambulatory clinic setting. Nat Clin Pract Urol. 2009;6(3):146-153.

40. Furman C, Caplan R. Applying the Toyota Production System: using a patient safety alert system to reduce error. Jt Comm J Qual Patient Saf. 2007;33(7):376-386. 